\title{
En Vogue: The Risks of Brexit to the European Fashion Industry
}

RYAN ESPARZA ${ }^{1}$

\section{Contents}

Introduction

I. Background
a. Brexit
b. European Union Design Protections
c. UK Design Protections

II. Brexit Could be Harmful to the European Fashion Industry if a Deal is Not Reached

a. Potential Harm to the EU Fashion Industry and Designers

b. Potential Harm to the UK Fashion Industry and Designers

i. Loss of Community Design Protections

ii. The "Forever 21 Effect"

iii. Issues with The Hague System for the International Registration of Industrial Designs

III. An Agreement Between the EU and the UK Could Lead to Stronger Global Design Protection

IV. Minimizing Harm Post-Brexit

V. Conclusion

\section{INTRODUCTION}

Coco Channel, Yves Saint Laurent, Gianni Versace, and Thomas Burberry, all iconic names that are synonymous with fashion and the fashion industry. Further, they are all European designers. From Paris Fashion Week to Milan Fashion Week, Europe is arguably the center of emerging fashion. It can be theorized that the reason for strong intellectual property rights within the European Union (EU), in the area of fashion design, is due to the significance of the fashion industry within Europe. ${ }^{2}$ Within the EU, there has long been a recognition of the significance of design protection, which sets its IP protection apart from other places in the world. ${ }^{3}$ Several of the protections that the EU has implemented can be traced back historically to attempts by the countries in the region to protect their textile markets, and to protect regional innovations which were being developed within early textile industries. ${ }^{4}$ Even in the early stages of the EU's history, there were attempts to create uniformity within the area of design. ${ }^{5}$ The desire to create uniformity in this area is continuous, but Brexit threatens a path towards uniformity.

Brexit represents the destabilization of the uniformity the EU desires for fashion design and its associated intellectual property rights. With the imminent exit of the United Kingdom (UK) from the EU on the horizon, an exit deal with the UK is necessary if the EU seeks to further its uniformity goals. An agreement between the two would be

\footnotetext{
${ }^{1}$ C Ryan Esparza 2018. The author is a recent graduate (JD) of the University of Mississippi School of Law, Oxford, MS.

${ }^{2}$ Alexandra Manfredi, Haute Copyright: Tailoring Copyright Protection to High-Profile Fashion Designs, 21 Cardozo J. Int'l \& Comp. L. 111, 113 (2012).

${ }^{3} I d$.

${ }^{4}$ Jacqueline Lampasona, Discrimination against Fashion Design in Copyright, 14 J. Int'l Bus. \& L. 273, 280 (2015).

${ }^{5}$ Council Directive 98/71, 1998 O.J. (L. 289) (EC).
} 
beneficial to both sides and would work to further expand the protections of the fashion industry rather than soften them. A hindrance of the design right protections the EU provides is that they are so robust that the lack of uniformity among non-EU countries induces a negative effect on the holder of the design right outside the EU. Adding the UK to the list of countries who do not conform to EU fashion protections does not improve the EU's established design rights.

For the EU, Brexit threatens the harmonization of fashion design IP protection as it will remove the UK from the EU IP regime. If the EU wishes to secure and strengthen the design rights of designers in the Member States, then there must be cooperation with other non-EU countries. This is necessary because lack of harmonization among nonEU countries may provide an avenue for infringers to circumvent EU protocols due to the inconsistency of design right protections globally. For the UK, Brexit could result in weaker protections which might leave room for companies to more easily steal designs, thus hurting UK designers. American fashion retailer Forever 21 is known to infringe on designers' catwalk collections by sending pictures of said collections to Forever 21 factories in China where they can be reproduced in a little more than two weeks. ${ }^{6}$ Forever 21 has been the leader for this form of infringement on designs within the fashion industry, so for the purposes of this article, this type of infringement will be referred to as the "Forever 21 Effect." To avoid this potential harm to the European fashion industry a deal must be reached between the EU and the UK, which addresses the goals of harmonization of the EU through the furtherment of design protections for fashion pieces and ensures the UK maintains strong IP protections for its designers.

This note consists of six parts. Part I provides background information on Brexit and the existing protections provided by the EU and those specific to the UK. Part II will discuss the detrimental effects that an exit by the UK would have on the industry of both countries should a deal between the EU and the UK not occur. Part III discusses the positive aspects a deal could have by the furthering the uniformity the EU desires for its design protections and discusses potential actions on the parts of the UK and the EU if an agreement is not reached. Part IV examines methods which could be utilized to minimize the harm of Brexit if a deal between the EU and the UK fails to happen. Finally, Part V will conclude the examination of the UK and EU's fashion industry, and will offer a potential outlook on the future of this area should the UK and EU either fail to compromise on an agreement or manage to successfully negotiate an exit.

\section{BACKGROUND}

\section{a. Brexit}

As early as 2012, then UK Prime Minister David Cameron hinted at the possibility of a future referendum to gauge the support of the people of the UK for continued membership in the EU. ${ }^{7}$ David Cameron did not support a referendum to leave the EU, and instead was largely using referendum talks as a negotiation tactic. ${ }^{8}$ However, despite opposition from David Cameron, in 2016 a referendum was held to determine the fate of the UK's membership within the EU. ${ }^{9}$ The movement to leave the EU was largely backed by the UK Independence Party (UKIP), about half of the Conservative Party's Members of Parliament (MPs), and a small number of MPs from the Labour Party and Democratic Unionist Party (DUP). ${ }^{10}$ On June 23, 2016, a vote on the referendum took place, and the decision to leave the EU was sealed with $51.9 \%$ voting to leave and $48.1 \%$ voting to remain with an overall turnout of $71.8 \%$ for eligible voters. ${ }^{11}$

On March 29, 2017, current Prime Minister Theresa May initiated the two-year process to withdraw from the EU. ${ }^{12}$ The process of withdrawing from the EU is detailed in Article 50 of the Lisbon Treaty. ${ }^{13}$ According to Article

\footnotetext{
${ }^{6}$ Jenna Sauers, How Forever 21 Keeps Getting Away With Designer Knockoffs (2011), https:/jezebel.com/5822762/howforever-21-keeps-getting-away-with-designer-knockoffs.

${ }^{7}$ Adam Fleming, David Cameron 'prepared to consider EU referendum' (2012), http://www.bbc.com/news/uk-politics18659072.

${ }^{8} \mathrm{Id}$.

${ }^{9}$ Alex Hunt \& Brian Wheeler, Brexit: All you need to know about the UK leaving the EU (2018), http://www.bbc.com/ news/uk-politics-32810887.

${ }^{10} I d$.

${ }^{11} I d$.

${ }^{12}$ Hunt, supra note 7.

${ }^{13}$ Consolidated Version of the Treaty on European Union art. 50, 2010 O.J. C 83/01, [hereinafter TEU post-Lisbon].
} 
50, any Member State may withdraw from the EU in accordance with their constitutional requirements. ${ }^{14}$ Upon deciding to withdraw, a Member State is required to notify the European Council, and a process of negotiation shall take place between the State and the Union. ${ }^{15}$ Once a withdrawal agreement is entered into or two years have elapsed since the notification of withdrawal, which may be extended through an agreement between the Member State and a unanimous Council, EU law shall cease to apply to the withdrawing State. ${ }^{16}$ The UK is scheduled to leave on March 29, 2019, and if no deal comes to pass then the UK would have to operate under already existing rules and laws which are likely to be less favorable than those afforded to them as a Member State in the EU. ${ }^{17}$

\section{b. European Union Design Protections}

Directive 98/71/EC is the key source of harmonized design protections for the EU and defines a design as the overall appearance or a portion of the production which derive from "the lines, contours, colours, shape, texture and/ or materials of the product itself and/or its ornamentation." 18 The directive requires the Member States to protect designs by registration, and provide exclusive rights to the holders of the registration in accordance with the directive. ${ }^{19}$ In order to achieve protection of a design, it must be of novel and individual character ${ }^{20}$ If the design is applied to or incorporated into "a product which constitutes a component part of a complex product," then there are two requirements in order to be novel and have individual character. ${ }^{21}$ The component part must remain observable during typical use, and those observable features themselves fulfill the standard requirements of novelty and individual character. ${ }^{22}$

Once the design right protection is conferred, the scope of protection includes any design "which does not produce on the informed user a different overall impression." ${ }^{23}$ Further, upon registration, this protection may be renewed for a maximum of 25 years. ${ }^{24}$ However, the scope of protection exhausts when the holder of the design right, or a party acting with their permission, places the product into "the market in the Community." 25 Directive 2001/29/EC implemented the World Intellectual Property Organization Copyright Treaty (WIPO Copyright Treaty) and acted to largely harmonize several aspects of copyright law across Europe, notably the reproduction right and exceptions. ${ }^{26}$

Council Regulation (EC) No 6/2002 is possibly the most modern advancement within the EU regarding design protection. It is intended to work in conjunction with Directive 98/71/EC. ${ }^{27}$ The regulation established a uniform system of industrial design rights. ${ }^{28}$ The regulation defines any designs meeting the criteria contained in the regulation as a Community design. ${ }^{29}$ The regulation makes the distinction between two types of Community designs, registered and unregistered. ${ }^{30}$ The regulation maintains the same definitions and requirements listed within Directive 98/71/EC but additionally provides that the benefits listed in that directive apply to registered

${ }^{14} I d$.

${ }^{15} \mathrm{Id}$.

${ }^{16} \mathrm{Id}$.

${ }^{17}$ Hunt, supra note 7.

18 See Directive 98/71/EC of the European Parliament and of the Council of 13 October 1998 on the legal protection of designs.

${ }^{19}$ Id.

${ }^{20}$ Id. art. 3.

${ }^{21} I d$.

22 Id.

${ }^{23}$ Directive 98/71/EC, supra note 16 at art. 9.

24 Id.

${ }^{25} I d$.

${ }^{26}$ See generally Directive 2001/29/EC of the European Parliament and of the Council of 22 May 2001 on the harmonization of certain aspects of copyright and related rights in the information society.

${ }^{27}$ Council Regulation No 6/02/EC of 12 December 2001 on Community designs.

${ }^{28} \mathrm{Id}$.

${ }^{29} \mathrm{Id}$.

${ }^{30}$ Id. at art. 1. 
Community designs. ${ }^{31}$ Notably, eligible designs may be registered within one year of introducing it to the public and may achieve protection for a maximum of twenty-five years. ${ }^{32}$ Unregistered Community designs can only achieve protection for a maximum of three years which begins with it first being made available to the public within the Community. ${ }^{33}$

The primary distinction between registered and unregistered Community design, apart from the length of protection, involves the type of acts a right holder may prevent. ${ }^{34}$ A registered Community design holder maintains the exclusive right to use the design and to prevent any party who does not get the consent of the right holder, from use. ${ }^{35}$ Some of the rights of a registered Community design holder includes "the making, offering, putting on the market, importing, exporting or using of a product in which the design is incorporated or to which it is applied, or stocking such a product for those purposes." ${ }^{36}$ An unregistered Community design holder may prevent the previously mentioned acts only if the acts are the result of copying without the holder's consent. ${ }^{37}$

In addition, some of the benefits conferred by Council Regulation (EC) No 6/2002 include the right of the designer to be cited as such before the Office and in the register. ${ }^{38}$ Further, there is acknowledgment for teams of designers and their contribution to the design. ${ }^{39}$ The regulation also states that the rights conferred to a designer may also vest to a designer's successors. ${ }^{40}$ If the design was jointly developed by two or more people, then the rights conferred by Community design vests in the team jointly. ${ }^{41}$ Further, contested use will not qualify as copying if the design was the result of independent creation by a designer who was not familiar with the original design made available to the public. ${ }^{42}$

\section{c. UK Design Protections}

The UK does maintain some of its own protections which would allow for the protection of designs originating from within the UK. This would be some of the established laws the UK could turn to in the event a deal could not be brokered between the UK and the EU. The Registered Designs Act 1949 and the Copyright, Designs and Patents Act 1988 are the primary sources of design protection in the UK.

The Registered Designs Act of 1949 maintains the same definition of a design as the EU, defining it as "the appearance of the whole or a part of a product resulting from the features of, in particular, the lines, contours, colours, shape, texture or materials of the product or its ornamentation." 43 Further, the act establishes the same requirements as the EU by also requiring that designs be novel and have individual character. ${ }^{44}$ The rights afforded to rights holders are also similar as they allow for control of "the making, offering, putting on the market, importing, exporting or using of a product in which the design is incorporated or to which it is applied; or stocking such a product for those purposes." ${ }^{4}$ In addition, the length of registered protections of designs extend for a maximum of twenty-five years, and similar to the EU, the registration has to be renewed every five years. ${ }^{46}$ The act itself reflects similar language, including benefits, requirements, and limitations, to the EU's protections for registered designs. ${ }^{47}$

${ }^{31} I d$.

${ }^{32} I d$.

$33 \mathrm{Id}$. at art. 11.

34 Directive 2001/29/EC, supra note 24.

${ }^{35} I d$.

${ }^{36} I d$.

${ }^{37} \mathrm{Id}$.

38 Directive 2001/29/EC, supra note 24 .

${ }^{39} \mathrm{Id}$.

${ }^{40} \mathrm{Id}$.

${ }^{41} I d$.

42 Id.

43 See generally The Registered Designs, Act, 1949 (12, 13 and 14 Geo. 6 c. 88).

${ }^{4} \mathrm{Id}$.

${ }^{45} I d$.

${ }^{46} I d$.

${ }^{47} \mathrm{Id}$. 
The Copyright, Designs and Patents Act 1988 reiterates a lot of the major points already established in the EU and UK regarding registered design rights. ${ }^{48}$ The purpose of the act was to create another category of design protection which differed from The Registered Designs Act of $1949 .{ }^{49}$ The act in particular addresses unregistered design rights within the UK. ${ }^{50}$ The act defines the designer as the first owner of the design right, and it does place limitations on designs which may be produced in the course of business or commission. ${ }^{51}$ Where the difference between the UK and EU significantly come through are for this area of unregistered designs. ${ }^{52}$ The most notable difference is the duration of the design right. ${ }^{53}$

Under the act, the design right expires fifteen years after it was recorded in a document or ten years from the first sale. ${ }^{54}$ These laws demonstrate that if the UK were to leave the EU without a deal, then UK designers would still be able to obtain some protection. Further, due to the UK's initial desire to streamline and harmonize IP protections with the EU, which is why there is such consistency between the UK and EU design protection, the protections that designers would receive in the UK would be similar to those protections in the EU. ${ }^{55}$ However, UK designers would no longer have access to the convenient EU system of design protections which extends across the Member States of the EU. ${ }^{56}$ This will likely result in increased difficulty for UK designers achieving similar success due to the problems they would have protecting their original designs.

\section{Brexit Could be Harmful to the European Fashion Industry if a Deal is Not Reached}

The EU fashion industry's primary goal is to ensure that global intellectual property rights are strengthened. ${ }^{57}$ The easiest route to achieving this goal is likely through reaching agreements with other countries. Designers would likely gravitate to areas where design protection is strongest. ${ }^{58}$ If Europe, specifically the EU, wants to maintain its renowned status within the global fashion industry, then reaching an agreement would make significant strides to achieve that. Reaching an agreement with the UK would be a significant step towards ensuring IP strengthens in a manner suitable to the EU, and it would act in furtherance of their harmonization goals. Without a deal, the likelihood that the EU is successful in harmonizing design rights globally becomes even more difficult.

The UK fashion industry is at risk of creating a potential atmosphere where infringers may take advantage of weaker design rights protections. The EU offers its Member States stronger protections than the UK due to the extensive region in which protections apply and because the UK's protections are narrower in scope. ${ }^{59}$ The UK's weaker protection scheme provides a clear path upon which infringers could take advantage. With weaker protections to rely on, designers could suffer from economic loss due to potential competition an infringer utilizing the "Forever 21 Effect" could impose.

If an agreement is not reached between the EU and the UK, then there is a risk to European designers and the industry in the area. The lack of an agreement could create an atmosphere which allows a new source of infringement to develop and take advantage of the lack of design protections between the EU and the UK, and which would make cooperation in the area of cross-country IP protection more difficult to achieve.

\footnotetext{
${ }^{48}$ See generally Copyright, Designs and Patents Act 1988 (c. 48).

${ }^{49} I d$.

${ }^{50} I d$.

${ }^{51} I d$.

${ }^{52} I d$.

${ }^{53} I d$.

${ }^{54}$ Copyright, Designs and Patents Act 1988, supra note 46.

${ }^{55}$ Christopher Smith, The UK IP Bill: harmonizing UK and European design protection (2014), https://www.reddie.co.uk/ 2014/03/05/the-uk-ip-bill-harmonizing-uk-and-european-design-protection/.

${ }^{56} I d$.

${ }^{57}$ Fischer, supra note 53.

${ }^{58}$ Lynsey Blackmon, The Devil Wears Prado: A Look at the Design Piracy Prohibition Act and the Extension of Copyright Protection to the World of Fashion, 35 Pepp. L. Rev. 107, 142 (2007).

${ }^{59}$ Deborah Kirk and Elizabeth Purcell, IP \& Brexit: The Impact of Brexit on the Community Unregistered Design Right and the Creative Industries Who Rely on Them (2017), https://www.latham.london/2017/10/ip-brexit-the-impact-of-brexit-on-thecommunity-unregistered-design-right-and-the-creative-industries-who-rely-on-them/.
} 


\section{a. Potential Harm to the EU Fashion Industry and Designers}

The harm Brexit presents to the EU fashion industry and its designers is the destabilization of the EU's design protection harmonization goals. ${ }^{60}$ The destabilization of the EU's harmonization goals would not just affect the simplicity of designers utilizing the legal system within the EU and UK, but would also affect the application of design right protections themselves. The lack of harmonization could ultimately lead to the design rights of the designers within the EU becoming weakened due to infringers taking advantage of more lenient design protections in non-EU countries.

There are countries where design rights do not conform to the rigorous design right protections that the EU provides. ${ }^{61}$ Weaker protections may provide an avenue upon which infringers may strategically limit their activities to certain countries in order to take advantage of that country's weaker IP protections. For example, the UK's unregistered design right does not protect patterns or colours while in the EU these may be protected under unregistered Community design or registered Community design in the EU. ${ }^{62}$ This is an instance where infringers could take advantage of this lack of protection in the UK if a deal is not made between the EU and UK. A path which furthers harmonization between the two territories would be a means of circumventing such activity. Therefore, harmonization between the EU and the UK would be beneficial because it could potentially set forth a path upon which the EU could build. Instead of breaking away from the EU's desire to increase global conformity among the area of design, and IP rights overall, a deal could be the start of a more globalized design right.

Another area of concern for the EU and its designers could likely be the increase in design right procedures and costs which a lack of harmonization could bring. EU right holders will need to register with the UK and EU if they wish to protect against infringement in both territories. ${ }^{63}$ In addition to creating added steps upon which designers would have to navigate, registration in more than one territory, this would likely result in an increase in litigation procedures and litigation costs for designers in order to protect their rights. ${ }^{64}$ This would be due to the necessity of designers having to register and then protect design rights in two territories. Assuming designers have met the requirements for registered or unregistered designs in both territories, then to protect those rights, designers will have to have one proceeding in an EU court and another in a UK court. ${ }^{65}$ If the EU can negotiate proper terms with the UK then, in addition to furthering the EU's harmonization goals, a deal could potentially prevent the previously mentioned increase in litigation. Further, costs associated with a designer protecting their designs against infringement would likely be less of a concern with a more centralized litigation system for the design right.

The final potential issue that the EU may face by failing to reach a deal with the UK is the souring of relations between the two territories. This could potentially lead to the UK purposely modifying or passing laws that are counter to the EU goals of harmonization. Currently, the UK limits its unregistered design protection to persons who are nationals or residents of the EU or nationals of New Zealand and Hong Kong. ${ }^{66}$ If a deal does not come forth then there may be a possibility that the UK could modify the language of its own laws to maintain less friendly terms for the EU. ${ }^{67}$ As previously mentioned, the reason that UK design right protections are likely similar to those of the EU is likely due to a one-time desire to conform and harmonize with the goals of the EU. ${ }^{68}$ However, if no deal is worked out between the two, little motivation remains for the UK to continue this trend. Therefore, it would be in the best

${ }^{60}$ Florian Traub \& Gillian M. Dennis, Brexit-What Could Happen to My IP Rights? 29 Intell. Prop. \& Tech. L.J. 20, 22, 29

NO. 11 Intell. Prop. \& Tech. L.J. 20, 22.

${ }^{61}$ See Fischer, supra note 53.

${ }^{62}$ See Copyright, Designs and Patents Act 1988, supra note 46; see also Sarah Redmond, Legal Advice: Fashion, designs and Brexit (2017), http://cwb-online.co/legal-advice-fashion-designs-brexit/.

${ }^{63}$ Sauers, supra note 5.

${ }^{64} I d$.

${ }^{65} I d$.

66 UK \& EU Unregistered Designs (2017), available at http://mewburn.com/wp-content/uploads/2017/06/UK-EUUnregistered-Designs-The-Basics.pdf.

${ }^{67}$ See Sally Shorthose, Brexit: English Intellectual Property Law Implications (2017), 22 No. 1 Cyberspace Lawyer NL 5 (stating that UK's exit from the EU would affect the unitary efforts dedicated to harmonizing IP rights.).

${ }^{68}$ See Anna Tischner; The role of unregistered rights - a European perspective on design protection, 13 J. Intell. Prop. L. \& Prac. 1, 303, 303-14 (2018). 
interests of the EU to reach a deal with the UK in order to ensure they remain minimally affected by the UK's exit from the EU and also ensure their harmonization goals are minimally affected.

\section{b. Potential Harm to the UK Fashion Industry and Designers}

If no agreement is reached between the UK and the EU, then all current protections between them will end. ${ }^{69}$ There is no grandfather clause, there is no exception. When the deadline is reached it will mark an immediate and automatic cessation of Community design protections for those right holders in the UK. ${ }^{70}$ The result of this will lead to possible irreparable harm to UK designers if a deal is not reached by the deadline, or at the very least reached within a reasonable time after the deadline passes.

\section{i. Loss of Community Design Protections}

If the deadline for the UK and EU to reach an exit agreement passes, then UK will lose the EU protections afforded to registered and unregistered Community design right holders. No longer will the UK have access to the centralized EU protections which grant protections to designers in the Member States. This loss will mean the UK will lose registered Community protections which grant designers a max of twenty-five years, and unregistered Community designs which grant a max of three years after it has become available to the public within the Community. ${ }^{71}$

The primary issue which results from the loss of registered Community designs will derive from the loss of territorial protection. If the deal fails to come about between the EU and the UK, then the UK and its designers will lose protection over an extensive area due to the UK no longer being considered a Member State of the EU. ${ }^{72}$ To circumvent this, designers in the UK would need to register in both the UK and the EU. Theoretically, if a designer only registers in the UK, then an infringer could go to France and commit the infringement there. There would be no readily available recourse that the designer could utilize unless they also register with the EU. As mentioned in the previous section, having to seek out protection in two different territories increases the procedures upon which designers have to navigate, and also increases the cost for designers to protect against infringement in these territories. $^{73}$

Currently, the UK is included in the Member States upon which a designer with the EU could protect their designs, so designers do not necessarily have to worry about navigating multiple systems of protection unless they choose to register in countries outside of the EU. If no deal is reached between the EU and the UK, then designers in the UK will need to register in two territories. If designers in the UK do not register in the two territories, then designers have to worry about their potential designs being infringed upon by an infringer in any of the EU Member States. This would be different because currently, UK designers do not have to concern themselves with an advantageous infringer, at least in most of Europe, because if they register with their designs with the EU they are largely protected within the entirety of the region. The fate of registered Community design right largely depends on the relationship between the EU and the UK, which is currently not the amiable. ${ }^{74}$

While the registered design rights UK and EU mirror each other for the most part, the UK's unregistered design protections deviate extensively from the EU. ${ }^{75}$ First, the term in which an unregistered design in the UK may be protected lasts for a significantly longer time than the EU. The UK's length of protection associated with

${ }^{69}$ See Traub, supra note 56.

${ }^{70} \mathrm{Id}$.

71 See Council Regulation No 6/02/EC, supra note 26.

72 Jim Miller, 'Brexit' \& designs (2017), available at http://www.kilburnstrode.com/assets/articles\%20\&\%20-briefing\% 20notes/Kilburn\%20\&\%20Strode_Brexit\%20and\%20designs-6.pdf.

${ }^{73}$ Estelle Derclaye; CUDR and CRDR post-Brexit from a UK and EU perspective-Will all unregistered design rights become history?, 13 J. Intell. Prop. L. \& Prac. 4, 325, 325-31 (2018).

${ }^{74}$ Marc Mimler, The Effect of Brexit on Trademarks, Designs and Other "Europeanized” Areas of Intellectual Property Law, Brexit: The International Legal Implications (2017) available at https://www.cigionline.org/-sites/default/files/documents/ Brexit\%20Paper\%20no.7web.pdf. in the United Kingdom.

75 UK \& EU Unregistered Designs (2017), http://mewburn.com/wp-content/uploads/2017/06/UK-EU-UnregisteredDesigns-The-Basics.pdf. 
unregistered designs is fifteen years after it was recorded in a document or ten years from the first sale. ${ }^{76}$ While this would appear to be an instance where the UK has superior design right protections than the EU, it is merely illusory. In fact, while the length of protection is longer than the EU, the scope of protection in the UK is narrower. ${ }^{77}$

Second, the UK unregistered design right requires that infringers have actual knowledge that the unauthorized dealing is infringement. ${ }^{78}$ In the EU no knowledge is necessary, whether the infringer willingly or unknowingly infringed is irrelevant for the right holder to protect their design. ${ }^{79}$ This a weakness in the UK's unregistered design right because it limits the circumstance in which a right holder may successfully protect their design. In the UK the requirement that there be knowledge weighs heavily as a burden on the designer. In the EU it is not a concern to determine whether or not the infringer had knowledge that they were infringing, because as long as a copy of a protected design has occurred without the designer's consent, then the right holder may protect against such infringement.

Third, UK unregistered design rights do not protect patterns or colours while unregistered Community design rights maintain the same protection as registered Community design rights and the UK registered design rights. ${ }^{80}$ The UK unregistered design right forbids protection on surface decoration while the unregistered Community design allows protection for the shape or decoration of the product. ${ }^{81}$ This is another instance where the UK's design right comes off as weaker compared with the Community design right. It further demonstrates that designers in the UK will suffer if they are to rely on UK design alone because they are weaker than the EU counterparts.

\section{ii. The "Forever 21 Effect"}

The Forever 21 Effect refers to a type of infringement utilized by companies, like Forever 21. Forever 21 has been the most predominant leader for this form of infringement on designs within the fashion industry. As of 2011, Forever 21 has been sued more than fifty times for allegations involving theft of designs from other designers. ${ }^{82}$ These accusations have been levied from "big brands like Anna Sui and Diane von Furstenberg to smaller, independent designers like Trovata, Foley + Corinna, and 3.1 Phillip Lim." 83 While designers show off their catwalk collection, Forever 21 can send or copy pictures of the collections and have them sent to their factories in China where they can be reproduced ${ }^{84}$ Designs that could normally take months to make by original designers can be reproduced and on store shelves by Forever 21 in a little more than two weeks. ${ }^{85}$

Forever 21 will make slight changes to the designs or attempt to make exact duplicates because they are not concerned with the possible infringement. ${ }^{86}$ The culture of the company is to settle cases rather than pay for licensing fees because it is often less costly that way. ${ }^{87}$ They are not inclined to change this practice either because often the settlement agreement includes a non-admission of guilt, compensation to the designer, and confidentiality agreements. ${ }^{88}$ It is also thought that the reasoning behind the success of Forever 21 is due partly to their ability to infringe the designs of various designers, and also the inability of intellectual property laws to deal with design protection in the fashion industry. ${ }^{89}$

\footnotetext{
${ }^{76}$ Copyright, Designs and Patents Act 1988, supra note 46.

${ }^{77}$ Kirk, supra note 58.

${ }^{78}$ Redmond, supra note 61.

79 Redmond, supra note 61.

${ }^{80}$ Redmond, supra note 61.

${ }^{81}$ Id.

${ }^{82}$ Sauers, supra note 5.

${ }^{83} \mathrm{Id}$.

${ }^{84}$ Susanna Monseau, European Design Rights: A Model for the Protection of All Designers from Piracy, 48 Am. Bus. L.J.
} 27,37 (2011).

${ }^{85} \mathrm{Id}$.

86 Sauers, supra note 5.

${ }^{87} \mathrm{Id}$.

${ }^{88} \mathrm{Id}$.

${ }^{89} I d$. 
Other entities could potentially take advantage of the "Forever 21 Effect" due to the lack of an explicit design right in other countries, like the United States. ${ }^{90}$ This provides an avenue for the "Forever 21 Effect" to be used continuously because, as mentioned above, unless there is an existing standard on how to treat fashion designs, it becomes a guessing game of which area of intellectual property can designs be associated with. While designers and the legal system are trying to determine the answer to how to treat designs, infringers are willing, ready, and able to take advantage of ambiguity in design rights.

If a deal between the EU and the UK does not come about then a void in protection would exist between those in the EU and those in the UK. Such a void created in the lapse of cooperation could theoretically allow entities to utilize the "Forever 21 Effect" and infringe on the design rights of UK designers in the EU or vice-versa. Even though the EU and the UK will maintain design right protections within their own territories if a deal is not reached, the "Forever 21 Effect" could become a method in which large fast-fashion entities with nefarious purposes could seek to utilize in order take advantage of a void in design protections. This type of infringement is more likely to harm designers in the UK due to the vast Member States in the EU which they will not automatically gain protection in. Those in the EU merely have to worry about the UK alone, but will still gain protection across the remaining Member States of the EU. The designers in the EU have to worry about the loss of protection in one country. The UK has to worry about the loss of protection in twenty-seven countries. By not coming to an agreement the EU and the UK run the risk of making the "Forever 21 Effect" more common within the region. However, after an exit from the EU without a deal, the "Forever 21 Effect" is more likely to harm designers in the UK to a more significant degree.

\section{iii. Issues with The Hague System for the International Registration of Industrial Designs}

The Hague System for the International Registration of Industrial Designs is an international registration for industrial design rights that has sixty-eight contracting parties including the EU and UK, as of March 2018. ${ }^{91}$ Registration occurs through the World Intellectual Property Organization (WIPO) and is limited only to those designers who are a national of or are domiciled in a country who is a Contracting Party to the agreement. ${ }^{92}$ The Hague System permits renewable protection of the design for a period up to twenty-five years in most cases but this can vary depending on the Contracting State. ${ }^{93}$ This is where The Hague System begins to diminish in its appeal. It does not maintain a singular harmonized system, even though it does get close to it. ${ }^{94}$ This is because the system provides for some modification on the part of the Contracting Parties which defeats the purpose of having a uniform system of protection..$^{95}$

Theoretically, a designer could potentially lose out on protecting their design because some element or standard was not met to gain protection in a specific country. ${ }^{96}$ Another significant downfall of the system is that it is limited to registered designs. No unregistered designs gain protection, meaning the system would be another hoop in which designers would be required to navigate. While it is better than no system at all, it falls short of being as beneficial to designers as EU Community design rights, which are harmonized across the Member States. So, while The Hague System would help UK designers in their ability to protect their designs, it would not put designers in as good a sphere of protection as they currently are under the EU design rights.

90 Sauers, supra note 5.

91 UK ratifies Hague Agreement for industrial designs (2018) https://www.gov.uk/government/news/uk-ratifies-hagueagreement-for-industrial-designs.

92 See generally The Geneva Act (1999) of the Hague Agreement Concerning the International Registration of Industrial Designs.

93 Id.

${ }^{94} I d$.

95 The Hague System of registration allows exception to its formalities including allowing Japan to require six different views of design in question while other countries require multiple view requirements. Further, Contracting Parties can modify the timing of registration. Richard S. Stockton, Hague weighed: Should I change my design filing strategy? (2015) available at https://bannerwitcoff.com/wp-content/uploads/2015/07/Hague-Weighed.pdf.

${ }^{96}$ Alana Fuierer, What You Need to Know About the Hague Agreement: Benefits and Potential Pitfalls (2015), http://www. hrfmtoday.com/2015/06/what-you-need-to-know-about-the-hague-agreement-benefits-and-potential-pitfalls.html. 


\section{An Agreement Between the EU and the UK Could Lead to Stronger Global Design Protection}

Design rights are territorial, which means that they are limited to a specific country or region. ${ }^{97}$ As mentioned previously, one of the core goals of the EU fashion industry is to ensure other countries maintain high design protection standards and that design protections as a whole continue to strengthen globally. ${ }^{98}$ Currently, no harmonized international design right systems exist. For a designer to achieve protection of various territories they have to meet the requirement for each territory and also register within those territories. ${ }^{99}$ The closet system to a harmonized international design right is The Hague System. However, as previously mentioned The Hague System is not perfect, nor is it truly harmonized across Contracting Parties.

Despite its flaws, The Hague System does present a core concept upon which the EU could attempt to model. With the additions of its strong registered and unregistered design right protections to a system like The Hague System, and its desire to reach a more harmonized IP protection status, the EU could take steps toward creating a true harmonized international design right. A deal between the EU and the UK could be a starting point in achieving such a goal. If the EU and the UK are able to come to an agreement, then it could provide a preview to other potentially interested countries, and provide these countries with a standard to look to if they are trying to reform design protections.

As previously mentioned one of the issues facing the EU, which derives from their strong design rights, is that other countries' weaker protection provides protentional avenues upon which infringers can take advantage. Regarding fashion law in the United States, Fordham University law professor and fashion lawyer Susan Scafidi said:

[T] rademark can be stretched to cover the label. Trade dress, a subset of trademark, stretched a little further to cover very iconic designs. Copyright pulled in to cover jewelry and to cover fabric prints, jewelry because it is like a little mini sculpture and not merely a useful article. Occasionally, patent pulled in to protect functional elements, like Velcro, or a zipper...So intellectual property sort of stretches these bits to cover parts of fashion, leaving most of fashion naked and exposed. Which is why the need for the additional law, to finally say, Look, we can cover the core as well. We can cover the central aspect of any garment, and that is its actual design, if it is indeed innovative. ${ }^{100}$

Using Scfaidi's example of the United States, an explicit design right does not exist within the United States. Instead, other areas of IP law must be used to protect designs. ${ }^{101}$ Other countries also have this same issue and it leaves open a flaw within the IP laws of certain countries upon which infringers can take advantage. For example, in the EU, if a violation of a designer's design right occurs they can bring action against an infringer for violating the design right. If the United States is once again used as an example, if an infringer copies a design they question, the issue then becomes what action do you charge them with. You have to examine whether a violation of copyright, patent, or trademark occurred, as opposed to one distinct area like design rights. This then incentivizes designers to protect their designs via other areas of intellectual property which may or may not cover the design.

An additional issue deriving from unharmonized IP protections is whether the proper steps were taken to protect the design. Further, whether the designer took the proper steps to register the design in question in the proper IP category presents additional steps designers need to navigate in countries with no design right. Following an exit from the EU, no longer will rights extended by the EU to its Member States be valid in the UK. ${ }^{102}$ While the design rights are similar between the UK and the EU, there are differences as mentioned above. The International Trademark Association (INTA) has adopted Model Design Law Guidelines, but they

${ }^{97}$ World Intellectual Property Organization, Frequently Asked Questions: Industrial Designs, http:/www.wipo.int/designs/ en/faq_industrialdesigns.html.

${ }^{98}$ Fischer, supra note 53.

${ }^{99}$ World Intellectual Property Organization, Frequently Asked Questions: Industrial Designs, http:/www.wipo.int/designs/ en/faq_industrialdesigns.html.

${ }^{100}$ Sauers, supra note 5.

${ }_{101}$ Sauers, supra note 5.

${ }^{102}$ Fischer, supra note 53. 
remain jurisdictionally neutral. ${ }^{103}$ This means that if territories adopted these guidelines for a design right category of IP law, then there would still be differing standards from country to country. ${ }^{104}$ It appears that achieving harmonization in itself is a difficult task which may be why such leeway is given to these methods of attempting harmonization; however, the EU may be able to lead global design protections if they can reach a deal with the UK.

If the EU and the UK come to an agreement on the treatment of design rights, then this could provide a view into the coordination and cooperation of two independent territories operating a joint design right system. While this would likely not have an immediate effect on the status of a harmonized global design right, what it may do is provide interested countries with an example of how the protections would work. The UK design right is available to citizens and companies from New Zealand and Hong Kong. ${ }^{105}$ If the EU manages to reach an agreement with the UK, perhaps it is possible that the UK could use its resources to convince these two territories to also join. It is a process that would take a significant amount of time. However, if the EU's goal is to make IP rights stronger globally, then the harmonization of design rights is a decent place to start without having to change countless IP standards across countries. It may lead the way for other countries to see the progress the EU and the UK are making, and make those countries more inclined to adopt the same standards of protection the EU provides. This, in turn, would contribute to succeeding in the harmonization of IP, which the EU fashion industry and designers desire.

\section{Minimizing Harm Post-Brexit}

States are bound to maintain protections associated with acquired rights. ${ }^{106}$ Failing to do so may violate the First Protocol to the European Convention of Human Rights (ECHR), most notably article 1 which protects the right to property. ${ }^{107}$ ECHR Protocol 1 provides that "[e]very natural or legal person is entitled to the peaceful enjoyment of his possessions." 108 Possessions are described shares, patents, licenses, leases, and welfare benefits provided they are enjoyed by a legal right and not by discretion. Peaceful enjoyment includes right of access and there is an obligation of states to protect the enjoyment of property rights. ${ }^{109}$ The reason why ECHR Protocol 1 may come into effect is largely due to the fact that if no deal is reached between the EU and the UK then right holders are left without recourse and they are likely to be deprived of the right to their property. ${ }^{110}$

A determination of whether such an argument under ECHR Protocol 1 would be successful is beyond the scope of this article; however, there is a possibility it may be used if there is going to be such a determining effect to those holding rights to designs. This means if the UK wants to avoid the possibility of an ECHR Protocol 1 violation, there are two options available to them. ${ }^{111}$

The first option, and most ideal, is the UK and the EU negotiate an arrangement which would continue the Community design right system after Brexit and treat Community design rights as an extension to the UK. This option could take place before Brexit occurs or after, depending on whether the parties feel like they are close to

103 Jean-Claude Darné, International Trademark Association Adopts Model Design Law Guidelines Document Provides the Framework to Advocate for Harmonization of Design Law (2017) https:/www.inta.org/Press/Pages/-Design_Law_Guidelines. aspx.

${ }^{104} I d$

105 Redmond, supra note 61.

106 "The International Court of Justice has held in several cases that private rights acquired according to law in force do not extinguish because of a change of sovereignty." See Derclaye, supra note 72 at 326 (citing J.C. Galloux, Le sort des droits (marques, dessins et modèles, appellations d'origine et certificats d'obtention végétale) délivrés avant le Brexit, Propriétés Intellectuelles 8 (2017).).

107 See Council of Europe, Protocol 1 to the European Convention for the Protection of Human Rights and Fundamental Freedoms, 20 March 1952, ETS 9. (hereinafter referred to as ECHR Protocol 1).

108 ECHR Protocol 1, supra 106.

${ }^{109} \mathrm{Id}$.

110 Derclaye, supra note 72 at 326.

${ }^{11}$ Since the UK is the party taking steps to deprive right holders of the design rights, they would likely be the responsible party for engaging in an ECHR Protocol 1 violation. Therefore, a large share of responsibility is placed on the UK to ensure such rights are not deprived. Derclaye, supra note 72 at 326. 
compromise. In addition, this option could allow for expansion of design rights across other non-EU countries. ${ }^{112}$ This would allow design right protections between the two to continue as they had pre-Brexit.

The second option, which itself has six different options, occurs if the UK and the EU do not reach a deal and it does not appear that either side is close to agreeable terms. This option is for either the UK or the EU to enact legislation that gives rights to the other. ${ }^{113}$ It is more likely that the UK would have to be the party enacting legislation which extends rights in the UK to Community design right holders in the EU. ${ }^{114}$ This is likely due to the EU being less than receptive, currently, to making an amendment to their own IP structure, the EU being less than receptive to any agreements the UK has put forth regarding IP rights, and the pressure of a possible ECHR Protocol 1 on the UK. ${ }^{115}$ The Chartered Institute of Trade Mark Attorneys (CITMA) has put forth five different mechanisms which the UK could utilize if the first option stated does not succeed. ${ }^{116}$

First, the UK could enact legislation which enforces Community design rights within the UK. ${ }^{117}$ This would require UK courts to treat Community designs as having effect in the UK. ${ }^{118}$ The issue with this sub-option is most notably the lack of legal certainty it would present and the high probability of post-division conflicts. ${ }^{119}$

Second, the UK enacts legislation which would establish all EU registrations as automatically UK registrations. ${ }^{120}$ The issues deriving from this sub-option largely come from the pressure it would place on the UK Intellectual Property Office (UKIPO).

Third, EU registrations would be registered with the UK, but only if a right holder chooses to extend registration to the UK. ${ }^{121}$ This is another option which would put further strain on the UKIPO because they would have to deal with an added application for those who would desire the extension of UK registration.

Fourth, is the same as the previous sub-option, but where the UK retains the right to refuse to allow an EU registration on the UK register. ${ }^{122}$ Like the first option, the legal certainty for this option is difficult due to the UK having no say over which EU registration they would allow. It could provide the potential for favoritism of UK design registrations over EU registrations.

Fifth, an EU right holder would have the option to create a corresponding UK registration when it renewed its EU design right. ${ }^{123}$ This option would require the dedication of a significant portion of the UKIPO's resources because there would be a need to track dates, renewal applications, and other like material. It may be too much of a strain to be viable.

The best route for the UK and the EU is to come to an agreement to protect the rights of designers. None of the sub-options unilaterally acceptable by the UK come without some kind of significant issue. Further, these suboptions do not address the unregistered design rights of designers. This means that registration would be the only means of people securing rights unless they met the requirements for unregistered design rights in both the EU and UK. If Europe wants to ensure designers and the fashion industry thrive in Europe, then it would be best to work together to develop an agreement.

${ }^{112}$ See CITMA, EU registered rights - trade marks (2017). https://www.citma.org.uk/membership/brexit/eu_registered_ rights_-_trade_marks; see also Derclaye, supra note 72.

${ }_{114}$ Derclaye, supra note 72 at 326.

${ }^{114} \mathrm{Id}$.

115 Brexit: The EU's proposed Withdrawal Agreement and IP (2018) https://www.marks-clerk.com/Home/KnowledgeNews/Articles/Brexit-The-EU\%E2\%80\%99s-proposed-Withdrawal-Agreement.aspx.

${ }^{116}$ CTIMA lists six potential sub-options upon which the UK can utilize. However, the sixth option is unpracticable to the extensive strain it would place on UK Intellectual Property Office registration along with the added costs it would provide. For this reason, it is left out of the available option to UK. CITMA, supra note 111.

${ }^{117} \mathrm{Id}$.

${ }^{118} I d$.

${ }^{119} \mathrm{Id}$.

${ }^{120}$ CITMA, supra note 111.

${ }^{121}$ CITMA, supra note 111.

122 CITMA, supra note 111.

${ }^{123}$ CITMA, supra note 111. 


\section{Conclusion}

Brexit presents several issues which the UK will need to address before it removes itself from the EU. Among this is the design right, which is significant to Europe because of the region's status within the fashion industry. If the UK and the EU wish to protect the European fashion industry and its designers, then they need to reach a deal. Not only will this ensure that Europe maintains its status among the elite when it comes to fashion, but it will further the harmonization goals of the EU. This could be the opportunity the EU wants to show other countries that design rights need harmonization and there could be no better opportunity to show this than reaching an agreement with the UK.

For the UK, a deal ensures they will retain the strong protections they were normally afforded, and it would prevent infringers seeking to use the "Forever 21 Effect" to harm designer's rights within the country. It would also protect those Community design right holders in the UK who will need to register in two territories, adding to the costs and procedures of the process. If the EU and the UK wish to secure protection for their respective fashion industries then it is necessary that the two make reasonable efforts to reach an agreement. If the two sides do not, then the result could be irreparable harm caused to both which will hurt one of the region's most popular and lucrative industries. 